\title{
Improving the Model of Family-School Interaction with the Help of Digital Education
}

\author{
Jamileh Alamolhoda ${ }^{1}$ \\ Accepted: 13 May 2021 \\ (C) California Association of School Psychologists 2021
}

\begin{abstract}
The study of the consequences of school education has proved the need for reinforcement family interventions in school education and also the need to improve the model of family-school interaction (FSI). The family and the school are two complementary educational institutions. But the emergence of digital technologies and especially the critical situation caused by the outbreak of coronavirus (COVID-19) has paved the way for their further interaction. However, both the family and the school have faced serious changes in their educational tasks and functions, and have raised questions about the possibility of upgrading the FSI and possible changes in curriculum. The present study is qualitative and the data collection tool is in-depth interview. Participators in the study are 24 teachers and parents of 6-11-year-old male and female learners who are involved in virtual education. Findings showed that virtual education in social, educational, cost-related, skill-related, emotional, and communication settings has a great impact and has created opportunities and challenges. This study also showed that in promoting family-school interaction, educational opportunities were the most significant and cost-related challenges were more than others. In addition, in order to promote family-school interaction, policies and strategies need to be identified that help in the equitable distribution of learning activities between parents and teachers and improve the model of family-school interaction according to the limited capacities of digital technologies.
\end{abstract}

Keywords Digital education · Virtual education $\cdot$ Curriculum $\cdot$ Family $\cdot$ School $\cdot$ Family-school interaction

\section{Introduction}

The family and the institution of education are two complementary educational spaces. Almost all religions and philosophical schools and all the great thinkers from the past to the present have emphasized the role of the family in education. In addition, most professionals, planners, principals, and teachers pay close attention to the role of the family in education (Farrell \& Collier, 2010). The significant effects of family and school participation on children's socio-behavioral skills and mental health have been confirmed by many studies (Sheriden et al., 2019).

The positive view of family-school interaction (FSI) is a developing approach and not only educators but also most policy makers, planners, and even many principals and teachers agree that FSI has useful educational results (J.

Jamileh Alamolhoda

Alamolhodaj@Gmail.com

1 Faculty of Education and Psychology Organization(s), Shahid Beheshti University, Tehran, Iran
Alamolhoda, 2020). Most experts and specialists consider "family educational participation in school education" a necessity and the only discussion is about how and to what extent should this type of participation take place. In other words, various studies have shown that there are two basic needs for promoting FSI. One is strategies to encourage families and increase family participation in school affairs (Wilkins \& Terlitsky, 2016) and the other is strategies to improve patterns of family intervention in school affairs (Laereau \& Munoz, 2012).

So far, some researchers have developed ideas about connecting with parents, family education, and reinforcement of the participatory and educational skills of parents (Pelco \& Ries, 1999) while others have focused on strategies that improve FSI (Sensiper, 2010).

However, FSI has undergone extensive changes over time. These include two recent events, the outbreak of COVID-19 and the closure of schools and universities and offices, and more leisure time for parents and learners and their stay-athome time, as well as the widespread use of digital technologies and virtual spaces. Hence, FSI has faced new challenges and opportunities. 
School haste in the use of digital technologies and the teacher's distance from learners, as well as the crisis caused by changes in the parents' business environment and unforeseen irregularities, have provoked these developments. These changes happened so quickly that both families and schools were confused about the optimal use of digital technologies and virtual spaces. Therefore, recognizing the challenges and opportunities of digital technologies at this critical time can help achieve better and more effective planning in the field of curriculum promotion, especially from the point of view of optimal FSI.

\section{Theoretical Background}

The scope of family-school interaction and the role of technology in improving and complementing this interaction can be described as follows.

Contrary to the popular belief, which emphasizes the individual-society duality and divides our human life into private or personal and public or social, some philosophers, including Allameh Tabatabai, give the family an independent identity and role in the middle of these two areas. According to Allameh Tabatabai, the private sphere is connected to the public sphere or the personal sphere to the social sphere only through the mediation of the family (M.H. Tabatabai, 1999). The family can pass on a wealth of knowledge and skills to the next generation through mother language teaching as well as through the transmission of customs and traditions. Since society expands primarily through childbearing, the best and most effective way to convey social values to these newcomers is through their implicit education through language and etiquette learning, which starts with the family from the earliest days of life.

According to Allameh Tabatabai, the basic concepts of social life such as the science of property, power, and beauty of the presidency and other concepts are formed in the mind of each person before entering the society (Tabatabai \& Motahari, 1996). In other words, children learn the important concepts of social life before entering society, and with the help of learning their mother language and customs, traditions, and communication in the family but to enter the public sphere and complex social life, they need written language formulations as well as other basic numbers and concepts that they need to learn in school.

The school curriculum in completing social education includes teaching language formulation in the form of reading and writing, logic, and grammar. These school-specific training programs can easily help children increase their insight into exchange relationships, power relationships, property relationships, and friendships and animosities and while becoming familiar with value exchange methods, expose to sufficient practice in using this method.
The important point is that the family cannot create the suitable space in developing the necessary knowledge and skills in the field of values. The family environment is so friendly and non-formal and full of love that it cannot reflect the complex and competitive relationships in the market and the company and the management of other social institutions well. The family and the friendly and informal relationships prevalent in it cannot make domination relationships understandable to children and to discipline the child's friendly and naively behavior. Any move towards a regular and calculated acquaintance of children with formal environments and complex social relationships in school can prevent children and adolescents from the inevitable and insurmountable failures and frustrations.

Therefore, it is necessary for children to adapt their knowledge, skills, and desires to social values in a more formal and non-intimate environment and with serious feedback. Contrary to popular belief, school-to-home simulation involves relatively large losses for the child; because it keeps him in childhood and naivety and makes the child unable to understand the relatively strict rules of the social life. Reducing school to home is an unforgivable mistake in completing social education programs. It should be noted that although the teacher needs to be like the parent, they should not completely replace the parent. The authority of the teacher depends on the position and tools of power that the teacher has. Any reduction of the teacher to facilitation or parenting is an unforgivable mistake in social education. On the other hand, delegating the responsibility of a teacher to parents, in addition to requiring a lot of educational knowledge and skills, is also in conflict with the role of parenting and the sincere relationship between parents. Therefore, in order to have a good social education program, equitable division of labor and family-school interaction should be emphasized as a basic necessity and any reduction of parenting to teacher or teacher to parenting should be avoided. Therefore, family-school interaction (FSI) is automatically a function of our beliefs about (1) the importance and role of the teacher, (2) the importance and role of parents, and (3) the relationship between the family and the school in completing the social education of the child.

The advent of digital technologies on the one hand and school education on the other has affected parenting. The advent of digital education has led to fundamental changes in the functioning of both the family and the school. Accordingly, we need research that can, with different assumptions about family and school educational responsibility, explain the role of digital technologies in the formation and development of formal and non-formal education programs and provide more detailed analysis of optimal and possible ways to make use of the digital technologies to promote FSI. Considering the importance of digital technologies in the educational functions of the family and school, as well as the interaction between them, the first questions we need to answer are the following: What 
kind of challenges does family-school interaction face in a digital learning environment and what opportunities can it take advantage of? What are the areas of improving and completing family-school interaction in the virtual education environment? What solutions and programs can be proposed to improve and complement the family-school interaction in the digital education environment? Therefore, the present study tries to answer these questions as much as possible.

\section{Methodology}

The present study has been conducted in the Iranian society. This research is phenomenological and has been done with a qualitative approach in primary education. Iran's general education system is in the form of a 12-year course and includes primary and secondary education, which are offered in the form of two types of schools: public and private. Private schools make up $12 \%$ of Iran's schools. The primary course is divided into 6 years and the secondary course is divided into two 3-year courses, namely the first and second secondary school. In all schools in Iran, there is the experience of family-school interaction and it is basically related to the role of the Parents and Teachers Association (PTA). In a small number of schools, there was limited virtual e-learning experience prior to the coronavirus outbreak. But after the outbreak of the coronavirus, virtual education spread through the Shad application (student education network), WhatsApp, LMS, and Telegram. In the present study, due to the special role that family-school interaction plays in the primary school, the focus is on this course.

Participants included teachers and parents of 6-11-year-old male and female students in public and private schools. The selection of participants was purposeful through snowball sampling (Gull et al., 2011). In this way, the next samples were selected by introducing the previous participants. Based on theoretical saturation in the data, their number reached 24 people. The average age of participants is 39 years. The criterion for selection was the experience of moving from face-to-face to virtual education. Therefore, the criterion for selection of parents was to have a child in primary school and to have at least 1 year of face-to-face school experience, as well as the virtual education experience. The criteria for selecting teachers was having at least 1 year of face-to-face teaching and three virtual teaching classes in the elementary school. Fifteen (62.5) of the participants (teachers and parents) in public schools and 9 (37.5) of the participants in private schools were involved. Eleven (45.83) of the participants in the study were male and 13 (54.17) of the participants were female. Ten (41.6) of the participants were teachers and 14 (58.4) of the participants in the study were parents. The level of education of the parents includes a range of people: 7 people with a bachelor's degree, 2 people with a master's degree, and 5 people did not go to university and had completed the general (secondary) course. Teachers: 7 people had a bachelor's degree and 3 people had a master's degree. The total number of participants was 19 with higher education, of which 10 had studied humanities, 6 had studied experimental sciences, and 3 had studied mathematics. The work process was in the form of in-depth interviews and with the Persian language that began with a general question about the benefits and concerns of the participants about virtual education. The duration of the interview lasted from 35 to $80 \mathrm{~min}$, depending on the interest and the amount of useful information that the participants were willing to present. At the beginning of the interview, while introducing the researcher and the research objectives, some general issues of virtual education were explained and often a suitable time and voice recording preparation was done. In some cases, the interview was repeated by the researcher for reassurance and the participant was asked to confirm, complete, or explain them further. The validity of the findings was reviewed and confirmed by evaluators ( 5 people). In order to analyze qualitative data and extract the categories from interviews, qualitative content analysis method was used.

\section{Results}

Based on the results of the analysis of the interviews, the categories related to the factors affecting the family-school interaction in the digital education environment have been extracted, which are described below.

From the text of 24 interviews, 81 propositions (codes) were extracted by determining meaningful sentences. After performing content analysis on the obtained propositions, 58 propositions were obtained in the second stage and 39 in the third stage. Accordingly, the following categories were identified as effective factors in family-school interaction in the digital education environment (Table 1).

As can be seen in Table 1, the influential components of family-school interaction in the digital education environment include social, educational, skill, cost, and emotionalcommunication settings. In the following, the challenges and opportunities that each of these factors can have in the familyschool interaction in digital education are discussed.
Table 1 The most important components in the field of family-school interaction in the digital education environment
Social settings

Educational settings

Skills settings

Cost-related settings

Emotional-communicative settings 


\section{Social Settings}

\section{Opportunities}

From the text of 24 interviews, 68 propositions (codes) were extracted by determining meaningful sentences. After performing content analysis on the obtained propositions, 58 propositions were extracted in the second stage and 39 in the third stage. Accordingly, the following categories were identified as social opportunities of digital education were identified in order to promote family-school interaction (Table 2).

\section{Challenges}

From the text of 24 interviews, 46 propositions (codes) were extracted by determining meaningful sentences. After performing content analysis on the obtained propositions, 29 propositions were extracted in the second stage and 18 in the third stage. Accordingly, the following categories were identified as social challenges of digital education were identified in order to promote family-school interaction (Table 3).

\section{Educational Settings}

\section{Opportunities}

From the text of 24 interviews, 93 propositions (codes) were extracted by determining meaningful sentences. After performing content analysis on the obtained propositions, 65 propositions were extracted in the second stage and 39 in the third stage. Accordingly, the following categories were identified as educational opportunities of digital education were identified in order to promote family-school interaction (Table 4).

\section{Challenges}

From the text of 24 interviews, 63 propositions (codes) were extracted by determining meaningful sentences. After performing content analysis on the obtained propositions, 42 propositions were extracted in the second stage and 28 in the third stage. Accordingly, the following categories were identified as educational challenges of digital education were identified in order to promote familyschool interaction (Table 5).

\section{Cost-Related Settings}

\section{Opportunities}

From the text of 24 interviews, 42 propositions (codes) were extracted by determining meaningful sentences. After performing content analysis on the obtained propositions, 30 propositions were extracted in the second stage and 17 in the third stage. Accordingly, the following categories were identified as cost-related opportunities of digital education were identified in order to promote family-school interaction (Table 6).

\section{Challenges}

From the text of 24 interviews, 41 propositions (codes) were extracted by determining meaningful sentences. After performing content analysis on the obtained propositions, 28 propositions were extracted in the second stage and 15 in the third stage. Accordingly, the following categories were identified as cost-related challenges of digital education were identified in order to promote familyschool interaction (Table 7).
Table 2 The most important components in the field of social opportunities of digital education in order to promote family-school interaction

\begin{tabular}{ll}
\hline Categories in the field of social opportunity & $\begin{array}{l}\text { Number of } \\
\text { interviewees }\end{array}$ \\
\hline $\begin{array}{l}\text { Grow the trust of home and school to each other through more interaction } \\
\text { Social development of students due to being in the circle of home-school interaction }\end{array}$ & $7,3,11,22$ \\
$\begin{array}{l}\text { Knowledge of the school characteristics, moral and behavioral issues of students as a } \\
\text { result of closer interaction with family }\end{array}$ & $3,5,12,18,20,24$ \\
$\begin{array}{l}\text { The growth of social justice through the establishment of educational justice as a result of } \\
\text { providing equal education in virtual space for all families }\end{array}$ & $4,9,13$ \\
$\begin{array}{l}\text { Responsibility of students and parents to school parents } \\
\text { Enriching students' time in the family through the diversity of virtual space }\end{array}$ & $2,8,14,23$ \\
$\begin{array}{l}\text { Dependence of children's education to family members and support the family from } \\
\text { school }\end{array}$ & $8,13,22$ \\
Mutual understanding of teachers and parents of each other's job characteristics & $6,7,15,16$ \\
\hline
\end{tabular}


Table 3 The most important components in the field of social challenges of digital education

\begin{tabular}{ll} 
Categories in the field of social challenges & $\begin{array}{l}\text { Number of } \\
\text { interviewees }\end{array}$ \\
\hline $\begin{array}{l}\text { Family breakdown and loss of meaning as a result of improper use of virtual space } \\
\text { Lack of support of the families for policies formulated in the field of digital education } \\
\begin{array}{l}\text { Emergence of adverse social impact of family resistance due to lack of familiarity with } \\
\text { digital education }\end{array}\end{array}$ & $\begin{array}{l}3,7,911,18,23 \\
4,10,15,19,24 \\
2,6,13,17,24\end{array}$ \\
\hline
\end{tabular}

\section{Emotional-Communicative Settings}

\section{Opportunities}

From the text of 24 interviews, 76 propositions (codes) were extracted by determining meaningful sentences. After performing content analysis on the obtained propositions, 52 propositions were extracted in the second stage and 36 in the third stage. Accordingly, the following categories were identified as emotional-communicative opportunities of digital education were identified in order to promote family-school interaction (Table 8).

\section{Challenges}

From the text of 24 interviews, 68 propositions (codes) were extracted by determining meaningful sentences. After performing content analysis on the obtained propositions, 45 propositions were extracted in the second stage and 31 in the third stage. Accordingly, the following categories were

Table 4 The most important components in the field of educational opportunities of digital education in order to promote family-school interaction

Categories in the field of educational opportunity

Increase of parental control over school functions due to involvement in virtual education

Motivate and compete for homework and sending it to the teacher through parental participations

The influence of parents in activating students who are always silent in the classroom in virtual education

Alignment of education and training methods of the family and school

Get more information on subjects as a result of parental cooperation

Increased parental supervision over educational content and evaluation methods

Family participation and use of their experiences in the teaching-learning process

Increase in students' imaginative creativity because of the interactive atmosphere created
Number of

interviewees

Using a variety of evaluation methods based on their individual interests and abilities because of the teacher knowing more about $1,3,12,22$ students through cooperation with parents

Reduction of the authoritarian exercise of school education at home as a result of more informal communication between school $6,13,19$ administrators and parents

More information for parents about their children's academic achievement

$8,14,22$

Increase in positive competition in providing effective education by schools due to greater parental involvement

$9,17,24$

Opportunity to standardize education as a result of equal education in the country

7,10

Forming a space of joy and hope at home to face with education

16

Informing the families about the education of other schools and increasing the power of choice

9,17

Providing additional training by the family

$2,5,8,12,18,21,24$

More opportunities to interact and provide education to families

$4,10,19$

Teachers review in their teaching methods

7,13

Familiarization of parents with cyberspace and various educational resources other than the teacher

7,21

Parents' understanding and familiarity with educational principles

5,14

The teacher gets to know the student's family

$3,12,18,24$

Use other teaching methods along with lectures

$1,3,17,22$

Follow up and supervise parents on teachers' teaching

$4,8,20$ 
Table 5 The most important components in the field of educational challenges of digital education

Categories in the field of educational challenges

Number of interviewees

Excessive parental help to children and, consequently, lack of proper learning in the homework provided to them

$3,9,23$

Less participation and involvement of learners in virtual education

$2,6,20$

Risk of passive teaching method if not properly planned

$4,8,13,24$

Illustrating concepts and educational materials

7,21

Lack of practical creativity

9

The heavy burden of increasing the responsibility of participating in the education of children on families

$1,2,10,17,21,24$

More emphasis on the appearance and beauty of educational materials due to the nature of virtual space

$3,9,18$

Lack of recognition of virtual education by some parents

$4,11,19,22$

Non-observance of evaluation principles as a result of less formal evaluation

$2,5,8,19,23$

The difficulty of the teachers work in responding to the unrelated expectations of the parents

3,12

Parental interference in the evaluation process

12,19

identified as emotional-communicative challenges of digital education were identified in order to promote family-school interaction (Table 9).

\section{Skills Settings}

\section{Opportunities}

From the text of 24 interviews, 53 propositions (codes) were extracted by determining meaningful sentences. After performing content analysis on the obtained propositions, 39 propositions were extracted in the second stage and 24 in the third stage. Accordingly, the following categories were identified as skills opportunities of digital education were identified in order to promote family-school interaction (Table 10).

\section{Challenges}

From the text of 24 interviews, 49 propositions (codes) were extracted by determining meaningful sentences. After performing content analysis on the obtained propositions, 32 propositions were extracted in the second stage and 21 in the third stage. Accordingly, the following categories were identified as skills challenges of digital education were identified in order to promote family-school interaction (Table 11).

\section{Discussion}

According to the findings of this study, digital technologies in all areas of social, educational, cost-related, skillsrelated, and emotional-communication have had a significant impact on family-school interaction (FSI). These effects are such that they bring both challenges and opportunities for family-school interaction. Exploring these challenges and opportunities for raising children has implications that need to be explained in the framework of school psychology concepts. One of the key concepts is the areas of learning that include knowledge, attitude, and skills. As can be seen in the findings, the effects of digital technology are quite obvious in these three areas, the most important of which are social growth, growth of responsibility, growth of trust, growth of motivation for progress in students, increasing children's creativity and imaginative skills, attention to students' interests by teachers and parents, fostering positive emotional creativity such as love and courage, attention to individual differences,

Table 6 The most important components in the field of cost-related opportunities of digital education in order to promote family-school interaction

Categories in the field of cost-related opportunity

Number of interviewees

The growth of more informal and closer communication between parents and school parents as a result of reducing the pressure of $2,7,14,17,20,22$ reciprocal home-school education costs relative to each other

Creating a positive attitude in promoting parent-school interaction as a result of Providing their obvious consumption needs instead of capital costs

Equal interaction of all parents with school parents with respect to equal access to education at the same cost

$4,9,12,16,23$ 
Table 7 The most important components in the field of costsrelated challenges of digital education

\begin{tabular}{ll}
\hline Categories in the field of cost-related challenges & Number of interviewees \\
\hline Increased costs of purchasing technology supplies and tools for the family & $6,14,24$ \\
Training costs for teachers and parents to use digital education & $3,9,15$ \\
Costs of producing digital education content & $2,8,12$ \\
\hline
\end{tabular}

promoting tolerance and developing a spirit of criticism, increasing digital capabilities, critical thinking skills, and problem solving. In addition, the interaction of digital technology and family-school interaction can provide good opportunities for the learners' personality formation. Learners have a better chance of developing self-esteem and developing individual abilities because they benefit more from the cooperation and like-mindedness of their parents and teachers in virtual education; but because their behavior is more under the control of family and school, they have less chance of curiosity and exploration and self-leadership. The interaction of family and school with the help of digital education in parts of socialization projects such as accepting living standards and the tendency to have simple social communication may be faster and more successful, but in other parts of such projects including higher risk taking, creativity, and social leadership, it might not be much helpful for learners. In addition, family-school interaction with the help of digital technologies can provide more opportunities for learners and parents of one or more schools to participate in each other's fascinating experiences and thereby increase the possibility of understanding, empathy, and trust and increase the chances of sincere and lasting friendship. The impact of digital technologies on promoting family-school interaction may also help improve student adjustment and the quality of their academic lives.
An important goal for family-school interaction is to complete the social education of learners, and it seems that given the role of digital technologies in social education, we need to think more seriously about how to manage the schools in this situation. Basically, managing the education system is one of the most important challenges that most developing countries face today. Because the growth of digital technologies has reduced the effectiveness of bureaucratic methods for managing education. Because the logic that governs the school is a logic that is based on legal criteria, the development of digital industries does not reflect this logic. Because bureaucracy is considered a twin of democracy and a way to regulate the behavior and thoughts of individuals in a society and strengthen social cohesion to achieve progress (Weber, 1917), industrial development and the principles of liberalism are more in line with market logic and emphasize participatory governance. In any case, whether we agree or disagree with liberalism and the free economy, it is necessary to distance ourselves fundamentally from traditional and bureaucratic methods of educational governance. In fact, one of the most important factors that have challenged educational bureaucracy and bureaucracy in general is the growth of digital technologies. Therefore, the use of digital technologies has long been emphasized in national documents of Iran, such as the Fundamental Reform Document of Education (FRDE), but there is still no serious idea about educational governance. Considering the role of digital technologies in organizing the

Table 8 The most important components in the field of emotional-communicative opportunities of digital education in order to promote family-school interaction

\begin{tabular}{lc}
\hline Categories in the field of emotional-communicative opportunity & Number of interviewees \\
\hline Control of students' academic anxiety by parents & 2,17 \\
Creating emotional support through the family during the family-school interaction & $6,18,22$ \\
Teachers' awareness of students' intra-family relationships through interaction with family & $5,9,19,23$ \\
Facilitation of the learning of features such as love, courage and bravery through symbolism in virtual space & $1,5,16,24$ \\
Reducing the stress of virtual education as a result of family-school interaction & $3,11,18$ \\
Paying more attention to the individual differences and mental characteristics of children through family-school interaction & $4,9,15,20$ \\
Learning the principles of discussion and conversation by the student as a result of parent-teacher involvement & $3,10,18,21$ \\
Facilitating communication for inactive and shy students with parental support & 12,19 \\
Formation of tolerance and critical spirit as a result of participating in home-school dialogues & 9,21 \\
Teacher-student intimacy because of parental mediation in this relationship & $2,6,10,17,23$ \\
\hline
\end{tabular}


Table 9 The most important components in the field of emotional-communicative challenges of digital education

Categories in the field of emotional-communicative challenges

Deficiency in providing communication and socialization skills training to learners due to physical absence from school

$4,7,11,18$

The emergence of emotional gaps as a result of lack of face-to-face contact in education

6,9

Depriving students of the teacher's moral role modeling due to lack of physical interaction with teachers

10,16

Cultivation of thinking related to virtual space and lacking the characteristics of collective and social presence

$9,14,24$

Degradation of human communication between students, teachers and family members as a result of improper use of virtual $3,12,18,22$ space

capacity of teachers and parents to improve the model of family intervention in school education, two suggestions can be made: changing the model of educational governance and changing the curriculum.

1. Changing the model of educational governance in order to promote family-school interaction with the help of digital technologies

Discussing the educational governance, it is necessary to note that the concept of governance creates an abstract space for discussing social harmony (Bevir, 2012). Since digital technology also has many effects on social interactions such as family-school interaction, attention should be paid in reviewing and modifying the effects of digital technologies to the pattern of educational governance. Today, education takes place in the form of three types of office, company, and network structures. Perhaps this is because organizational theories typically develop these three types of structures: the market, hierarchy, and the network. Of course, the development of each of these three structures depends on paying attention to one of the important processes in social interaction. Therefore, the focal point of hierarchy is control processes, and market development owes to and is focused on free competition, and network development depends on mutual trust. (Bevir, 2012).
Although digital technologies have accelerated the development of the above three structures, the simultaneous presence of these three structures in the field of education has created challenges. Hence, both the family and the school are faced with a paradox. On the one hand, the family is confronted with the rules of the school and its educational goals, which are formed in a hierarchical structure and carry out educational programs in accordance with the approved educational goals. On the other hand, it is opposed to various methods and attractive educational products that are produced by the market structure as well as the network structure. The school is caught in a similar paradox. On the one hand, the school is facing the expectations of the government and the hierarchy of a centralized educational system, and on the other hand, it is engaged in an unwanted competition with the producers of educational products that have been developed in the market and network structure. More interestingly, on the one hand, the government can control the behavior of teachers and school principals with the help of digital technologies, and on the other hand, companies that produce and distribute educational products with the help of digital technologies can expand the competition indefinitely. As a result, contrary to the teacher's opinion and specialized views of education and perhaps contrary to family goals, and based only on the two criteria of attractiveness and profitability, a large market of digital educational products emerges uncontrollably and

Table 10 The most important components in the field of skills opportunities of digital education in order to promote family-school interaction

Categories in the field of skills opportunity

Facilitate the teaching of various skills with the support of the family through illustration and animation

Increase learners' confidence with the support of parents and teachers through visual learning of skills

Integrate school-based education with life skills through parental involvement

Learning self-leadership skills in learning and independent learning by learners and parents with proper planning

Increase the digital and media ability of parents and teachers

Learn critical thinking and problem solving skills from learners and parents with proper planning

Learning professional technical skills from learners and parents with proper planning
Number of interviewees
$3,12,17,23$
$1,4,15,22$
$7,17,21$
$9,16,24$
$2,10,13,18,20$
$5,8,14$
$11,18,22$ 
Table 11 The most important components in the field of skills challenges of digital education

Categories in the field of skills challenges

targets the minds and hearts of children and youth. The risk of uncontrolled profiteering in the market of educational and cultural products is a strong reason to reform the pattern of educational governance.

Consistent with the results of this study, it seems that the crisis caused by COVID-19 has convinced school parents and families to manage the use of digital technology by children wisely and with controlled planning. So, first, family-school interaction can be a logical and correct way to protect children and adolescents against profiteers and regulating the market for educational products is only possible through family-school interaction. Second, we need to welcome new ways of governance with the help of digital technologies. Because the basis of family-school interaction is mutual trust, and network governance derives its capabilities from the mutual trust of stakeholders. These similarities could have implications for the governance of school, according to the network model. Third, in educational governance, parents, teachers, and planners are considered the three sides of governance and everyone pays more attention to the needs of children than their own needs and tastes. The knowledge and skills of planners and teachers can be complemented by the compassion of parents and what is most beneficial to children can be presented in the form of a curriculum. Fourth, just as the design and implementation of a program have different levels, network governance also needs to have decision levels. That means, to some extent, we still need a hierarchical structure to run a school and interact with the family. For example, the superiority of teachers' knowledge and skills automatically forces learners and parents to follow their wise opinions. Therefore, maintaining the authoritative position of the teacher is to some extent necessary to achieve good educational results. Fifth, mutual trust, which is the core of family-school interaction, relies on the knowledge and skills of teachers and expert planners on the one hand, and on parents' understanding and compassion on the other. Sixth, discovering the capacities of parents and respecting their position are the responsibility of teachers, just as it is the responsibility of parents to respect the status of teachers and to trust their methods. Seventh, to resolve theoretical or practical conflicts, the existence of private and public meetings of ideation and planning is very necessary. Educational governance requires understanding of ideas and executive determination to avoid chaos and at the same time, to welcome good ideas from the multitude of ideas.
Eighth, rhetorical skills of teachers and planners need to replace formal and legal authority. This means having rhetorical abilities and succeeding in justifying and convincing parents and learners on their own can put them at the center of the educational governance network. Ninth, establishing five types of communication in family-school interaction with the help of digital technology can, on the one hand, develop educational governance in a network model and, on the other hand, increase the risk of this governance. These five types of relationships or five ways of communication are the following: professional communication between teachers with each other; experiential-educational communication between teachers and parents; experimental-educational communication between parents and each other; entertainment-educational communication of learners with each other; and tripartite communication between teachers, parents, and learners.

2. Curriculum changes for promoting family-school interaction with the help of digital technologies

The curriculum consists of a series of components or elements influencing education that some authors have considered four of which include goals, content, methods, and evaluation (Tyler, 1949). And some consider more than eleven influential and important elements for the curriculum (Akker, 2010), but the suggestions obtained from reviewing the results of this study emphasize the four main elements of the curriculum, including goals, content, methods, and evaluation.

\section{2-1. Change in goals}

The results of this study show that it is necessary to make changes in school curricula in favor of increasing the freedom of action of learners and all three groups of teachers, learners, and parents, and especially to strengthen their creativity. The use of digital technologies in school education and especially in conjunction with FSI has provided the basis for changing curricula from behavioral standards to creativity. A misconception about justice means equality has led to educational justice being seen as educational equality. As a result, curricula have shifted to the imposition of standards of educational behavior on the teacher and the learner. Educational standards play a guiding role for teachers, principals, planners, all 
educators, and even parents. Educational standards prevent any initiative by a teacher or planner, etc., and act as an educational prison and restricting the freedom of learners. However, this research shows that while paying attention to equal educational opportunities, we can use digital technologies and parents' sympathetic interaction to make the program more flexible and to consider some diversity and inequality in the educational program. Although it is necessary to consider order and coordination in the consequences of educational programs, but it is better in the details of programs to increase diversity and strengthen creativity not only learners but also teachers and parents should be considered a goal. In addition, in order to regulate the educational programs that seem necessary to achieve national and global goals of education, the spring model of goals can be used instead of the hierarchical model of goals. (J. Alamolhoda, 2019). In the spring model of each main goal, the program is always present with more detailed goals, but the amount of emphasis on it varies.

\section{2-2. Change in content}

The results of this study show that FSI accompaniment is very important for the use of digital technologies in the production of diverse and multi-level content. Contents such as electronic content, multimedia, educational software, interactive tools, games, simulations, and computer programs that enhance the knowledge, insight, and skills of teachers, learners, and parents need to be produced and properly distributed. These diverse contents with the help of FSI make it possible to achieve a flexible educational program tailored to the educational needs of learners.

Producing a variety of content for subjects in formats (electronic, multimedia, Internet), educational software, and interactive tools, in addition to enhancing the skills of teachers, learners, and parents, can help our experiences of combining games and lessons. FSI experiences in content production with the help of digital technologies can prevent curricula from sinking into entertainment while saving children from the excessive rigidity of educational content. These experiences can help set learning opportunities with a logical and calculated plan to focus on useful entertainment alongside the lesson.

\section{Method}

The results of this study show that the integration of FSI with digital technologies can create a context in which active training methods become much more objective and operational than in the past. The five relationships that are achieved in the shadow of FSI and with the help of digital technologies can change the teaching methods to more active methods. Learners in this situation learn not only to receive information but also to play an active role in teaching-learning. Children's superiority in using digital technologies today becomes a threat to the position of teachers and parents and encourages children to be rebellious. But the space created by FSI can turn this challenge into an opportunity because on the one hand, children enter the teaching-learning process as educators and get involved in specific issues of this process, and on the other hand, teachers have to work hard to improve their knowledge and skills and also it changes the attitude of parents and teachers towards them. However, mutual respect and mutual trust depend on maintaining the position of each individual or group involved in their own or another's training. A fair appreciation of the activities of everyone involved in FSI can help sustain and enhance it and improve training experiences.

\section{2-3. Evaluation}

The results show that with the integration of FSI with digital technologies, it is possible to diversify educational evaluations and also increase their validity. That is, by using different types of evaluations (individual, group, and self-evaluation) and using different evaluation techniques and methods (test, project, open-ended questions, surveys, etc.), the evaluation results can be compared and their validity can be challenged. In addition, integration of FSI with digital technologies provides the basis for common school evaluations such as one-stage (final), twostage (initial and final), and three-stage (initial-intermediate-final) evaluations which are changed to continuous and participatory evaluations. Faster and fairer feedback on evaluation results can change learning motivations. Therefore, according to the educational experience and with the participation of parents, it is necessary to adapt assessment methods and tools to the motivations of learners.

Diversifying FSI-based evaluation with the help of digital technologies can provide the basis for attention to creativity and various abilities such as the ability to memorize or analyze data and the ability to describe content in learners. It is both fascinating and dangerous that each learner and parent can evaluate other people, such as teachers and parents and other learners. Because although this can help complete the teaching-learning process, it may also lead to unwise judgments and annoyances and network disruption, so any difficult decisions in this case should be assigned to FSI.

\section{Limitations}

Despite the useful contributions that this study has made to the field of family-school interaction, it has had its limitations. The most obvious limitation is in generalizing the results, which should be taken with caution in extending it to other communities. Also, due to the limitations of the coronavirus, there was no access to family and school professionals to form a focus group and a panel of experts to discuss the findings of the present study with a larger number of experts. 


\section{Conclusions}

For some time now, most specialists have been emphasizing the benefits of using digital technologies to reduce the limitations of face-to-face education. Educational administrators have introduced programs for schools to use this type of technology in educational programs. Even policy and program documents, agreements, and contracts have been prepared in most countries, including Iran. However, the problems caused by the outbreak of the coronavirus (COVID-19) have led to significant changes in the use of digital technologies in schools. In addition, the widespread holiday caused by the outbreak of coronavirus has increased the strength of FSI and almost made it a major factor in the academic success of 10- to 6-year-old learners. Examining the challenges of the hasty and unplanned use of digital technologies by schools and families, along with exploring the opportunities and benefits of using digital technologies to educate children aged 610 , was the subject of interviews with a number of teachers, mothers, and fathers. Overall, the results of this study showed that the reinforcement of FSI with the help of digital technologies is essential to achieve educational goals. In addition, the results of this study showed that in order to improve FSI and also for the optimal use of digital technologies, two types of changes in school education are necessary: one is changes related to the management and governance structure of the school and the other is changes related to goals, content, teaching methods, and evaluation of school programs. Therefore, it is suggested that all countries, especially national and international educational institutions, set policies and plan to protect children's rights and prevent family confusion and prevent the development of profitable programs for the sale of educational tools and materials. Undoubtedly, planning focuses on the development of public participation, Reinforcement parental knowledge, reinforcement of the skills and educational knowledge of teachers, and encouraging families to actively participate in school education and encouraging professionals, scientists, and thinkers to create new ideas and model and appropriate to the changing conditions and situations of learners in different countries as well as encouraging ethical investors to participate in the economy and investing in the production of optimal educational programs and content are the focus of this type of policy.

\section{Declarations}

Ethics Approval All procedures performed in studies involving human participants were in accordance with the 1964 Helsinki declaration and its later amendments.
Informed Consent Written informed consent was obtained from all participants included in the study.

Conflict of Interest The author declares no competing interests.

\section{References}

Akker, J. V. D. ( 2010). Curriculum Design Research. In: Akker, J. V. D., Bannan, B., Kelly, A. E., Nieveen, N., \& Plomp, T. ( 2010). An Introduction to Educational Design Research, 3rd print, Netzodruk,; Enschede.

Alamolhoda, J. (2020). Areas for Reforming and Complementing the Family and School Interaction. The Open Family Studies Journal, 12, 1-9.

Alamolhoda, J. (2019). The eslamic theory of education. In Islamic and west research center Available at: http:/gsia.tums.ac.ir/en/VDRA/ ndt/353722/Introduction-of-the-Islamic-Research-and-informati.

Bevir, M. (2012). Governance: A Very Short Introduction. Oxford University.

Farrell, A. F., \& Collier, M. A. (2010). School personnel perceptions of family-school communication: a qualitative study. Improving school, 13(1), 4-20.

Gull, M., Bork, W., \& Gall J. (2011). Qualitative and qualitative research methods in educational sciences and psychology. Translators by Ahmad Reza Nasr ... [et al.]. SAMT.

Laereau, A., \& Munoz, V. L. (2012). "You are not going to call the shots": structural conflicts between the principal and the PTO at a suburban public elementary school. Sociology of Education, 85, 201-218.

Pelco, L. E., \& Ries, R. R. (1999). Teachers Attitudes and Behaviors towards family-school Partnerships. School psychology international, 20(3), 265-277.

Sensiper, S. (2010). Generating family-school partnerships through social marketing. Social Marketing Quatrterly, 5(1), 16-21.

Sheriden, S. M., Smith, T. E., \& Kim, E. M. (2019). A meta-analysis of family- school interventions and children social- emotional functioning: Moderators and components of efficacy. Review of educational Research, 89(2), 296-332.

Tabatabai, M. H. ( 1999). Tafsir Al-Mizan, Volume 4 , : Amirkabir Publication

Tabatabai, M. H., \& Motahari, M. ( 1996). Principles of Philosophy and Method of Realism, Volume 2, : Sadra.

Tyler, R. (1949). Basic principles of curriculum and instruction. University of Chicago Press.

Weber, M. (1917). Science as a vocation. In B. Barber \& W. Hirsch (Eds.), The Sociology of Science (pp. 569-589). Free Press.

Wilkins, J., \& Terlitsky, A. B. (2016). Intervention in school and clinic, 51(4): 203-211.

Publisher's Note Springer Nature remains neutral with regard to jurisdictional claims in published maps and institutional affiliations.

Jamileh Alamolhoda is an associate professor at Shahid Beheshti University of Tehran and a faculty member of the Faculty of Education and Psychology. She holds a PhD in Islamic Education from Tarbiat Modares University in Tehran. She is interested in studying in the areas of education policy, family and educational psychology. 